\title{
Aeromonas spp.: An Emerging Nosocomial Pathogen
}

\section{Priyam Batra, Purva Mathur, Mahesh C Misra' ${ }^{1}$}

\author{
Division of Microbiology, Department of Laboratory Medicine and 'Surgery, JPNA Trauma Centre, All India Institute of \\ Medical Sciences, New Delhi, India
}

Address for correspondence: Dr. Purva Mathur, E-mail: purvamathur@yahoo.co.in

\section{ABSTRACT}

Aeromonads are hallophillic, nonacid fast, nonspore forming, Gram-negative rods which are widely distributed in the soil, foodstuffs, and aquatic environment. Since times immemorial, they are important zoonotic pathogens of poikilotherms but are now emerging as important human pathogens. These emerging enteric pathogens flourish in the water distribution system by forming biofilms. They possess large number of virulence factors including inherent resistance to various antibiotics and ability to form biofilms using quorum sensing. These properties make them easy pathogens for human infections. Aeromonads are important enteric pathogens, but, with the growing level of immunosuppression in the population, they have been associated with various extraintestinal infections, such as skin and soft-tissue infections, traumatic wound infections, and lower respiratory tract/ urinary tract infections. The average annual incidence of bacteremia in Southern Taiwan due to Aeromonas spp. was 76 cases/ million inhabitants between 2008 and 2010. However, the incidence reported from Western countries is much lower. The case fatality rate among patients with Aeromonas bacteremia ranges from 27.5 to $46 \%$. Aeromonads are universally resistant to the narrow-spectrum penicillin group of antibiotics such as penicillin, ampicillin, carbenicillin, and ticarcillin. They are however susceptible to piperacillin, azlocillin, second and third generation cephalosporins, and carbapenems. Most of the Aeromonas species are susceptible to aminoglycosides, tetracycline, chloramphenicol, trimethoprim-sulfamethoxazole, quinolones, and monobactams. This manuscript is a comprehensive systematic review of the literature available on Aeromonas spp.

Key words: Aeromonas, emerging pathogen, immunocompetent

\section{INTRODUCTION}

 he Aeromonads are halophilic, Gram-negative, rod-shaped, nonspore forming, nonacid-fast facultative aerobes which are widely distributed in the soil, foodstuffs, and aquatic environment. ${ }^{[1]}$ These emerging enteric pathogens flourish in the water distribution system by forming biofilms in the water channels. ${ }^{[2]}$ They are responsible for a number of diseases of poikilotherms, such as red leg disease in frogs and ascites in carp. ${ }^{[3]}$ Humans carry Aeromonas species in the gastrointestinal tract, and the rates of fecal carriage vary from $0 \%$ to $4 \%$ in persons with no disease to $0.8-7.4 \%$ in persons with diarrheal illness. ${ }^{[2]}$ Most Aeromonas spp. particularly those associated with

\begin{tabular}{|c|c|}
\hline \multicolumn{2}{|c|}{ Access this article online } \\
\hline Quick Response Code: & $\begin{array}{l}\text { Website: } \\
\text { www.jponline.org }\end{array}$ \\
\hline 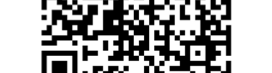 & $\begin{array}{l}\text { DOI: } \\
\text { 10.4103/0974-2727.176234 }\end{array}$ \\
\hline
\end{tabular}

human infections are found in a wide variety of fresh produce, meat, and dairy products. ${ }^{[2]}$

Historically, genus Aeromonas was included in the family Vibrionaceae with the other genera such as Vibrio, Plesiomonas, and Photobacterium. Colwell et al. in 1986 established a separate family Aeromonadaceae after phylogenetic investigation. Separation of Aeromonas spp. from the genera Vibrio and Plesiomonas depends on resistance to the vibriostatic compound $\mathrm{O} / 129$, no growth in $6 \%$ sodium chloride, and absence of ornithine decarboxylase activity (except in $A$. veronii biovar veronii). ${ }^{[4]}$ The three main pathogenic species

This is an open access article distributed under the terms of the Creative Commons Attribution-NonCommercial-ShareAlike 3.0 License, which allows others to remix, tweak, and build upon the work non-commercially, as long as the author is credited and the new creations are licensed under the identical terms.

For reprints contact: reprints@medknow.com

How to cite this article: Batra $\mathrm{P}$, Mathur P, Misra MC. Aeromonas spp.: An emerging nosocomial pathogen. J Lab Physicians 2016;8:1-4. 
of the genus are Aeromonas bydrophila, A. caviae, and A. sobria. ${ }^{[5]}$ These biochemically distinct species have now been subdivided into DNA hybridization groups. ${ }^{[2]}$ In humans, they were classically known to be associated with gastrointestinal infections only. They are also known to cause various extraintestinal and systemic infections such as urinary tract infections, sepsis, empyema, and peritonitis. ${ }^{[6]}$

\section{VIRULENCE FACTORS}

Aeromonas spp. are known to possess all the virulence factors which help in the establishment of infection. The presence of fimbria, flagella, and capsule helps in the attachment of the bacteria to the host surface. They then derive iron from the host using various iron-binding proteins such as siderophores to enable survival of the pathogen within the host. Survival within the host is followed by the production various exotoxins and enzymes such as proteases, elastases, lipases, and hemolysins to cause extensive cell and tissue destruction. Type II and III secretion systems in the bacteria enable them to evade the host immune response. Capsule, S-layer, lipopolysaccharides, and porin also enhance the pathogenic resistance mechanisms by compromising the host defense. ${ }^{[5,7]}$

Certain $A$. bydrophila strains contain a gene called aerocytotoxin enterotoxin (ACT) that releases a toxin (aerolysin) to cause tissue damage. Aerolysin, a cytolytic exotoxin, binds to specific glycoreceptors on the surface of eukaryotic cells before inserting into the lipid bilayer and forms holes. Aeromonas strains causing loose stools possess an alt gene which encodes for a heat labile cytotonic enterotoxin while patients with more severe disease and watery diarrhea had strains with alt and $A S T$ gene. AST gene produces a heat stable cytotonic enterotoxin. ${ }^{[8]}$

Aeromonas spp. have been shown to form biofilms on various biotic and abiotic surfaces which allow for the persistence of these pathogens in the water distribution system as well as in the human body. ${ }^{[5,7]}$ Quorum sensing molecules have been demonstrated from Aeromonas spp. (Aeromonas salmonocida and Aeromonas hydrophilla) which are responsible for the biofilm formation. ${ }^{[7]}$

Another major concern regarding Aeromonas infections is their potential resistance to penicillin, ampicillin, carbenicillin, and cefazolin as they possess at least 3 inducible chromosomal $\beta$-lactamases. Production of Ambler class $\mathrm{B}, \mathrm{C}$, and $\mathrm{D}$ beta-lactamases has been recognized in Aeromonas spp. Metallo-beta-lactamases (MBL), AmpC beta-lactamases, and penicillinases are the principle beta-lactamases harbored by Aeromonas. ${ }^{[7,9]}$ Extended spectrum beta-lactam (ESBL) producing Aeromonads are also being increasingly reported. ${ }^{[10]}$ The most common MBL produced by Aeromonas species is of the "CphA" type. Such MBL producing strains are resistant to the narrow and ESBL group of antibiotics but are susceptible to monobactams such as aztreonam. ${ }^{[7]}$

\section{INCIDENCE RATE, CLINICAL FEATURES, OUTBREAK SITUATION}

Aeromonads have been known from times immemorial to cause gastrointestinal disease in humans. They have been associated with diarrheal disease ranging from acute diarrhea in immunocompetent adults to chronic diarrhea in children, elderly, and immunocompromised individuals. They are also an important cause of travelers' diarrhea. Evidence supporting the causative role in diarrheal disease includes (1) a higher carriage rate in symptomatic compared with asymptomatic individuals; (2) an absence of other enteric pathogens in most symptomatic patients harboring Aeromonas spp.; (3) identification of Aeromonas enterotoxins linked to diarrhea; (4) improvement of diarrhea with antibiotics active against Aeromonas spp. and clinical worsening with antibiotics ineffective against the organism; and (5) evidence of a specific secretory immune response coincident with diarrheal disease. ${ }^{[1]}$ Aeromonas caviae is the predominant isolate from diarrheal stools, but, in some geographic areas, $A$. bydrophila and $A$. veronii biovar sobria have also been isolated. Aeromonas-associated diarrhea usually occurs during the summer, when the concentration of Aeromonads in water is the highest. ${ }^{[7]}$ Complications of Aeromonas diarrheal disease include hemolytic uremic syndrome or kidney disease requiring renal transplantation. ${ }^{[7]}$

Aeromonads have been associated with various extraintestinal diseases also, such as skin and soft tissue infections, traumatic wound infections, and lower respiratory tract/urinary tract infections. Disease pattern can vary from uncomplicated wound infections to fatal fulminant cellulitis and necrotizing fasciitis. Only $17-52 \%$ of wound infections are monomicrobial. The most common isolates obtained from patients with polymicrobial infections are Enterococcus species, Clostridium species, and enteric bacilli. The most common species associated with wound infection is Aeromonas bydrophila.

Aeromonas septicemia has been shown in patients having severe hepatic diseases, diabetes, cancer, leukemia, and immunosuppression due to other causes. ${ }^{[12]}$ Dissemination 
of the pathogen secondary to septicemia can give rise to meningitis, peritonitis, pneumonia, or urinary tract. In these patients, the source of infection is either from the gastrointestinal colonization or due to some other colonized site or from wound infection. A recent study showed that the average annual incidences of bacteremia in Southern Taiwan due to Aeromonas spp. was 76 cases/million inhabitants between 2008 and 2010, which was higher than those in Western countries. ${ }^{[12]}$ The case fatality rate among patients with Aeromonas bacteremia ranges from 27.5 to $46 \% .^{[13]}$

A variety of other infections caused by Aeromonas spp. have been reported including intraabdominal abscess, hepatobiliary infection, spontaneous bacterial peritonitis in patients with cirrhosis, meningitis, endocarditis, suppurative thrombophlebitis, osteomyelitis, urinary tract infection, pneumonia including near-drowning-associated pneumonia, empyema, lung abscess, tonsillitis, and otitis media.

\section{DIAGNOSIS}

These organisms are best identified using culture, Gram stain, and biochemical tests. A positive oxidase reaction, growth in nutrient broth without $\mathrm{NaCl}$, no growth in nutrient broth with $6 \% \mathrm{NaCl}$, inability to grow on thiosulfate citrate bile sucrose agar and resistance to the vibriostatic compound 0/129 help in the differentiation of Aeromonadaceae from Vibrio and pleisiomonas genera. The most common human pathogenic species (Aeromonas caviae, A. hydrophilla, and A. veronii biovar sobria) can be differentiated based on the microbiological examinations, including Voges-Proskauer test, fermentation of L-arabinose, esculin hydrolysis, and gas production from glucose. ${ }^{[1,2]}$ Though these are the best methods for identification, they are very time consuming requiring up to 48-72 h. Automated systems such as Vitek 2 or Microscan walk/away or BBL Crystal can also be used for the identification. These systems can identify the organisms within $24 \mathrm{~h}$ with $90 \%$ sensitivity of identification.

Most serological assays have low sensitivity and specificity and are generally not reliable. An IgA fecal antibody response to Aeromonas somatic lipopolysaccharides and exotoxins has been reported to be reliable. Polymerase chain reactions are rapid, convenient, and specific for the identification of the pathogen.

\section{ANTIBIOTIC SUSCEPTIBILITY PROFILE AND RESISTANCE MECHANISMS}

Antibiotic susceptibility testing can be done by the disc diffusion method using Mueller-Hinton agar and microbroth dilution method using cation-adjusted Mueller-Hinton Broth as per the Clinical and Laboratory Standards Institute (CLSI) guidelines ${ }^{\left[{ }^{[4]}\right.}$ However, most of the susceptibility data of CLSI are based on studied of the three predominant species only.

Aeromonads are universally resistant to the narrow-spectrum penicillin group of antibiotics such as penicillin, ampicillin, carbenicillin, and ticarcillin. They are however susceptible to piperacillin, azlocillin, second and third generation cephalosporins, and carbapenems. Most of the Aeromonas species are susceptible to aminoglycosides, tetracycline, chloramphenicol, trimethoprim-sulfamethoxazole, quinolones, and monobactams. ${ }^{[2,7]}$ Clinical isolates of Aeromonas caviae are more susceptible to ticarcillin than $A$. veronii and $A$. bydrophilla. $A$. veronii has greater susceptibility for cefazolin than $A$. cavia and $A$. bydrophilla. ${ }^{[2]}$

\section{INFECTION CONTROL/VACCINATION}

Most of the infections caused by the Aeromonas spp. are gastrointestinal infections. These can be easily prevented by maintaining adequate sanitary conditions such as hand hygiene, efficient sewage disposal, and hygienic food preparation. Proper cooking of the food product also minimizes the transmission. Adequate disposal of the diseased animal and water treatment can prevent the spread of Aeromonads. Continuous monitoring of the quality of water is essential to minimize the health risk due to Aeromonads. ${ }^{[2,7]}$

\section{TREATMENT}

Gastrointestinal diseases are generally self-limiting, and no antibiotic treatment is generally required. Treatment with rehydration therapy is generally adequate. Antibiotic prophylaxis may however be required in immunocompromised patients. ${ }^{[2]}$

Financial support and sponsorship

Nil.

Conflicts of interest

There are no conflicts of interest.

\section{REFERENCES}

1. Abott SL. Aeromonas. In: Baron EJ, Pfaller MA, Jorgensen JH, Yolken RH, editors. Mannual of Clinical Microbiology. $8^{\text {th }}$ ed. Washington DC: ASM Press; 2010. p. 701-5. 


\section{Batra, et al.: Aeromonas spp. an emerging pathogen in immmunocompetent patients}

2. Igbinosa IH, Igumbor EU, Aghdasi F, Tom M, Okoh AI. Emerging Aeromonas species infections and their significance in public health. Scientific World Journal 2012;2012:625023.

3. Slevin NJ, Oppenheim BA, Deakin DP. Aeromonas hydrophila septicaemia and muscle abscesses associated with immunosuppression. Postgrad Med J 1988;64:701-2.

4. Colwell RR, MacDonell MT, DeLey J. Proposal to recognize the family Aeromonadaceae fam. Int J Syst Bacteriol 1986;36:473-7.

5. Tomás JM. The main Aeromonas pathogenic factors. ISRN Microbiol 2012;2012:256261

6. Kimura M, Araoka H, Yoneyama A. Aeromonas caviae is the most frequent pathogen amongst cases of Aeromonas bacteremia in Japan. Scand J Infect Dis 2013;45:304-9.

7. Janda JM, Abbott SL. The genus Aeromonas: Taxonomy, pathogenicity, and infection. Clin Microbiol Rev 2010;23:35-73.

8. Albert MJ, Ansaruzzaman M, Talukder KA, Chopra AK, Kuhn I, Rahman M, et al. Prevalence of enterotoxin genes in Aeromonas spp. isolated from children with diarrhea, healthy controls, and the environment. J Clin Microbiol 2000;38:3785-90.
9. Chen PL, Ko WC, Wu CJ. Complexity of B-lactamases among clinical Aeromonas isolates and its clinical implications. J Microbiol Immunol Infect 2012;45:398-403.

10. Wu CJ, Chuang YC, Lee MF, Lee CC, Lee HC, Lee NY, et al. Bacteremia due to extended-spectrum-ß-lactamase-producing Aeromonas spp. at a medical center in Southern Taiwan. Antimicrob Agents Chemother 2011;55:5813-8.

11. von Graevenitz A. The role of Aeromonas in diarrhea: A review. Infection 2007;35:59-64.

12. Tang HJ, Lai CC, Lin HL, Chao CM. Clinical manifestations of bacteremia caused by Aeromonas species in southern Taiwan. PLoS One 2014;9:e91642.

13. Ko WC, Chiang SR, Lee HC, Tang HJ, Wang YY, Chuang YC. In vitro and in vivo activities of fluoroquinolones against Aeromonas bydrophila. Antimicrob Agents Chemother 2003;47:2217-22.

14. Clinical Laboratory Standards Institute. Performance Standards for Antimicrobial Susceptibility Testing; Twenty Third Informational Supplement CLSI Document M100-S23. Vol. 33. Wayne, PA: Clinical Laboratory Standards Institute; 2013. 